\title{
Effects of trematode infection on metabolism and activity in a freshwater snail, Semisulcospira libertina
}

\author{
Kazuko Shinagawa*, Misako U rabe**, Makoto Nagoshi***
}

Department of Biological Science, Faculty of Science, Nara Women's University, Kitauoyanishi-machi, N ara 630-8506, J apan

\begin{abstract}
Changes in the metabolism and activity of the freshwater snail Semisulcospira libertina infected with larval trematodes were studied experimentally. In snails up to $11 \mathrm{~mm}$ in shell width, crawling distance, feeding frequency, and the proportion of individuals located on vertical walls did not differ among snails infected with mature or immature cercariae, or uninfected snails $(p>0.05)$. In snails larger than $11 \mathrm{~mm}$, individuals infected with mature cercariae tended to feed more frequently during the light period $(p=0.0081)$, but the distance they crawled and the proportion of individuals located on vertical walls did not differ, regardless of infection $(p>0.05)$. Infection with mature cercariae significantly increased the oxygen consumption rate $(p=0.016)$, which was measured only in the large size.
\end{abstract}

KEY WORDS: Semisulcospira libertina $\cdot$ Larval trematodes $\cdot$ Activity $\cdot$ M etabolism

Resale or republication not permitted without written consent of the publisher

\section{INTRODUCTION}

Many studies have reported the behavioral alteration of hosts caused by parasitic infection and interpret this as an induced adaptation by parasites to facilitate transfer to the next-stage hosts. This 'manipulation' hypothesis has received much attention from evolutionary ecologists (Swennen 1969, Curtis 1990, 1993, Levri \& Lively 1996). However, ecological or behavioral changes also occur in hosts even when parasites are not dependent on predation for transfer to next-stage hosts, and the adaptive significance for parasites is unclear (Shinagawa et al. 1999a,b).

In J apan, a freshwater prosobranchia snail, Semisulcospira libertina (Gould), is the first-intermediate host

Present addresses:

*Fumigaoka-machi 15-18, Tondabayashi, Osaka 584-0094, Japan

**(Corresponding author.) J apan Science and Technology Corporation, Aqua Restoration Research Center, Kasada, Kawashima-cho, Hashima-gun, Gifu 501-6021, Japan.

E-mail: urabe55@pwri.go.jp

***Shimizu 856-36, Anno, M ie 514-2305, J apan of many species of trematodes (Ito 1964, 1988). We reported that snails infected with larval trematodes were found in deeper locations than uninfected snails (Shinagawa et al. 1999a). The pattern of water depth selection by infected and uninfected snails also differed under experimental conditions, although the pattern did not replicate field distribution (Shinagawa et al. 1999b). In contrast to field observations, large (shell width $>11 \mathrm{~mm}$ ) infected snails, especially those infected with immature cercariae or parthenitae, tended to select shallow sites relative to uninfected snails (Shinagawa et al. 1999b). Thus, factors other than the direct interference by parasites to water-depth selection by hosts affect the habitat shift of large infected snails in the field.

We examined crawling distance and feeding frequency as indicators of activity and physiological condition. These factors might cause a habitat shift in infected snails, as Semisulcospira generally feeds on the surface of stones or sediments while active and hides under stones or in sediments while resting (M ori 1946, Urabe 1998). The proportion of individuals located on vertical walls was also investigated to examine 
changes in adhesion since pathological changes in the foot surface of host gastropods were reported (Thompson et al. 1993). Oxygen consumption was measured to determine basal metabolism. These parameters were compared in small and large snails separately, since the effect of infection on water-depth selection differs according to host size (Shinagawa et al. 1999b). We discuss the possibility that changes in metabolism or activity resulting from infection cause the water-depth shift.

\section{MATERIALS AND METHODS}

All the snails studied were collected from the Takami River, Kotsukawa, Higashi-Yoshino, Nara Prefecture $\left(136^{\circ} 0^{\prime} \mathrm{E}, 34^{\circ} 24^{\prime} \mathrm{N}\right)$ between J uly and October 1995 or between A pril and October 1996. A total of 158 snails with a shell $>7 \mathrm{~mm}$ wide were collected for the laboratory experiment.

An aquarium with internal dimensions of $87 \times 42.5 \times$ $54 \mathrm{~cm}$ was used for the laboratory experiment. Three horizontal planes 4 to $6 \mathrm{~cm}$ wide were fixed at the bottom, middle and top of the aquarium. They were connected with ramps inclined at $33^{\circ}$. A paste of flour and fish pellet was provided as food at the 14 points on the planes and the ramps. The water was aerated and regulated at $20^{\circ} \mathrm{C}$. The aquarium was under a $13 \mathrm{~h}$ light and $11 \mathrm{~h}$ dark cycle. More details of the sampling location and the experimental conditions have been reported elsewhere (Shinagawa et al. 1999b).

Snails were measured for shell width and individually marked with color paint and released in the aquarium on the middle plane ( $27 \mathrm{~cm}$ deep). Six to 16 snails were used for 1 experimental session. After acclimatization for 24 to $38 \mathrm{~h}$, data recording began and continued for $48 \mathrm{~h}$. The location of each snail in the aquarium was recorded once every hour. We calculated the following parameters for the light and dark periods separately: mean crawling distance $h^{-1}(C D)$, feeding frequency (observed frequency of feeding per number of observations) ( $F$ ), and the frequency of location on vertical walls (observed frequency of location on vertical walls per number of observations) (V). The experiment was repeated 11 times, and each snail was used only once.

After the observation, 78 of the snails were selected randomly and oxygen consumption rate was measured. Individual snails were put in a $200 \mathrm{ml}$ bottle filled with water and kept in a $20^{\circ} \mathrm{C}$ incubator for $1 \mathrm{~h}$. Then the dissolved oxygen was measured by the Winkler method. The rate of oxygen consumption was calculated from the difference in dissolved oxygen between the bottles containing snails and a control bottle without snails.
After these experiments, the snails were dissected to determine trematode infection. The cercariae identified were Metagonimus sp. (experimental secondintermediate host, a freshwater goby, Rhinogobius flumineus, unpubl. data), Centrocestus armatus (second-intermediate host, cyprinid fish), Cercaria yoshidae (second-intermediate host, copepods), Cercaria innominata (second-intermediate host, fish: Shimazu, Nagano Prefectural College, pers. comm.), Cercaria nipponensis (life history unknown), and Cercaria $A$ by M akita et al. (1996) (life history unknown). An unidentified oculate furcocercous cercaria was also found. The snails were classified as uninfected snails ( $U$ snails), or snails infected with Metagonimus sp. (Mesnails), C. armatus (Ca-snails) or C. yoshidae (Cysnails). The other 4 species were not categorized for species because too few snails were infected. Snails infected with mature cercariae of any species, including 4 minor species, were grouped as ' $M$-snails'. Snails infected with unidentifiable immature cercariae or parthenitae were not categorized for species but classified as 'IM-snails'.

$C D, F$ and $V$ were compared among $U$-snails, IMsnails and each species category by Kruskal-Wallis test and multiple comparisons using the Bonferroni method. If the number of snails classified by trematode species was insufficient for statistics, M-snail was used as the category.

We divided the snails into 'small' (shell width up to $11 \mathrm{~mm}$ ) and 'large' (more than $11 \mathrm{~mm}$ ) size classes after Shinagawa et al. (1999b), to reduce the effects of size on measurements of physiological condition. The small size class comprised $34 \mathrm{U}$-snails, $5 \mathrm{M}$-snails (1 Casnail, 1 Cy-snail, 2 snails infected with Cercaria innominata and 1 snail with Cercaria A) and 3 IM -snails. The large size class comprised $77 \mathrm{U}$-snails, $20 \mathrm{M}$ e-snails, 5 $\mathrm{Ca}$-snails, $3 \mathrm{Cy}$-snails and $6 \mathrm{IM}$-snails. Five snails infected with mature cercariae (2 snails infected with $C$. innominata, 1 snail with $C$. nipponensis, 1 snail with the oculate furcocercous cercaria, and 1 snail doubly infected with $\mathrm{C}$. nipponensis and the oculate furcocercous cercaria) were excluded from the analysis but not the oxygen consumption rate determination.

In the 78 snails that were measured for oxygen consumption, all infected snails were more than $11 \mathrm{~mm}$ in shell width and in the large size class (minimum $11.6 \mathrm{~mm}$ ). Thus, the size effect on oxygen consumption could not be tested by division into the 2 size classes, unlike the other values. Therefore, the oxygen consumption rates of infected and large U-snails were compared using regression lines on shell size to determine size effect. Both the oxygen consumption rate and shell width were log transformed. For U-snails, only data for snails whose shell width was in the range of infected snails were selected for analysis (total $n=67$ ). 
Table 1. Comparison of crawling distance (CD), feeding rate (F) and the rate of location on vertical walls (V) among infection categories in each size class. Values were tested by Kruskal-Wallis test. Ca: snails infected with Centrocestus armatus; Cy: snails infected with Cercaria yoshidae; IM : snails infected with unidentifiable immature cercariae or parthenitae; $M$ : snails infected with mature cercariae of any species; Me: snails infected with Metagonimus sp.; U: uninfected snails. The mean values of $\mathrm{M}$-snails of the large size class are also shown, but these are not included in the statistical analysis

\begin{tabular}{|c|c|c|c|c|c|c|c|c|c|c|c|c|c|}
\hline \multirow{2}{*}{$\begin{array}{l}\text { Infection } \\
\text { category }\end{array}$} & \multirow{2}{*}{$\begin{array}{l}\text { No. of } \\
\text { snails }\end{array}$} & \multicolumn{4}{|c|}{$\longrightarrow$ CD } & \multicolumn{4}{|c|}{$\mathrm{F}$} & \multirow{2}{*}{\multicolumn{2}{|c|}{$\begin{array}{l}\text { Light } \\
\text { Mean p-value } \\
\text { (freq./26 times) }\end{array}$}} & \multirow{2}{*}{\multicolumn{2}{|c|}{$\begin{array}{l}\text { Dark } \\
\text { M ean p-value } \\
\text { (freq./22 times) }\end{array}$}} \\
\hline & & $\begin{array}{c}\text { Lic } \\
\text { Mean } \\
(\mathrm{cm}\end{array}$ & $\begin{array}{l}\text { ght } \\
\mathrm{p} \text {-value } \\
\left.\mathrm{h}^{-1}\right)\end{array}$ & $\begin{array}{r}\text { Mean } \\
(\mathrm{Cl}\end{array}$ & $\begin{array}{l}\text { ark } \\
\text { p-value } \\
\left(h^{-1}\right)\end{array}$ & 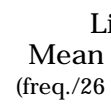 & $\begin{array}{l}\text { ght } \\
\text { p-value } \\
\text { imes } \times 100 \text { ) }\end{array}$ & $\begin{array}{r}D z \\
\text { Mean } \\
\text { (freq./22 }\end{array}$ & $\begin{array}{l}\text { ark } \\
p \text {-value } \\
\text { times } \times 100 \text { ) }\end{array}$ & & & & \\
\hline \multicolumn{14}{|c|}{ Small (shell width $\leq 11 \mathrm{~mm}$ ) } \\
\hline U & 34 & 13.4 & & 17.4 & & 6.2 & & 8.3 & & 0.45 & & 0.43 & \\
\hline M & 5 & 12.1 & $>0.05$ & 20.0 & $>0.05$ & 2.5 & $>0.05$ & 2.7 & $>0.05$ & 0.14 & $>0.05$ & 0.25 & $>0.05$ \\
\hline IM & 3 & 6.2 & & 30.4 & & 8.0 & & 1.5 & & 0.15 & & 0.41 & \\
\hline \multicolumn{14}{|c|}{ Large (shell width $>11 \mathrm{~mm}$ ) } \\
\hline $\mathrm{U}$ & 77 & 14.5 & & 22.3 & & 3.8 & & 8.1 & & 0.34 & & 0.31 & \\
\hline IM & 6 & 20.5 & & 22.4 & & 1.5 & & 6.3 & & 0.40 & & 0.25 & \\
\hline $\mathrm{Me}$ & 20 & 16.8 & $>0.05$ & 26.5 & $>0.05$ & 12.1 & 0.0081 & 10.6 & $>0.05$ & 0.32 & $>0.05$ & 0.36 & $>0.05$ \\
\hline $\mathrm{Ca}$ & 5 & 14.4 & & 32.1 & & 17.4 & & 14.3 & & 0.15 & & 0.28 & \\
\hline Cy & 3 & 16.8 & & 17.5 & & 14.7 & & 9.9 & & 0.21 & & 0.28 & \\
\hline$(\mathrm{M}$ & 33 & 15.1 & & 24.3 & & 12.4 & & 10.7 & & 0.27 & & $0.30)$ & \\
\hline
\end{tabular}

\section{RESULTS AND DISCUSSION}

$\mathrm{CD}, \mathrm{F}$ and $\mathrm{V}$ are compared in Table $1 . \mathrm{F}$ for the large size class in the light period was the only significant difference among the infection categories. Multiple comparisons did not detect significant differences between any pair of categories, although $\mathrm{Me}$-, $\mathrm{Ca}$ - and $\mathrm{Cy}$-snails tended to feed more frequently than $\mathrm{U}$-snails or IM-snails. CD and $V$ were not different among infection categories in the 2 size classes in either light or dark periods.

Fig. 1 shows the regression lines of oxygen consumption to shell width in large $\mathrm{U}$-snails and $\mathrm{M}$-snails. The correlations were not significant in IMsnails and the categories for each parasite species. In M-snails, the slope of the regression line was significantly different from that of U-snails $(F=6.15$, df $=1,65, p=$ 0.016). $M$-snails had a tendency to consume more oxygen than $\mathrm{U}$-snails, and this tendency is clearer in larger snails (shell width $>14 \mathrm{~mm}$ ) than in smaller ones.

In this study, we were unable to determine the influence of each trematode species separately, except Metagonimus sp., Centrocestus armatus and Cercaria yoshidae, because of the small sample size for each species. Therefore, we discuss the observed metabolic alterations from the viewpoint of general physiological effects of infection, such as nutrient deprivation.

The effects of trematodes on the metabolism (feeding frequency and oxygen consumption) of host snails and on water-depth selection (Shinagawa et al. 1999b) are dependent upon host size. Unlike that of the large snails, the presence or absence of infection did not affect $F$ of the small snails. Although we have no data on the respiration rate in the small size class, the difference between infected and $\mathrm{U}$-snails may well be smaller than that for the large size class, judging from the slope of the regression lines for the large snails. If that is the case, then infection would have a lesser influence on the metabolism of small snails than large snails.

Increased feeding with infection has been interpreted as compensating for the nutrient deprivation caused by parasites or as a modification of the host's

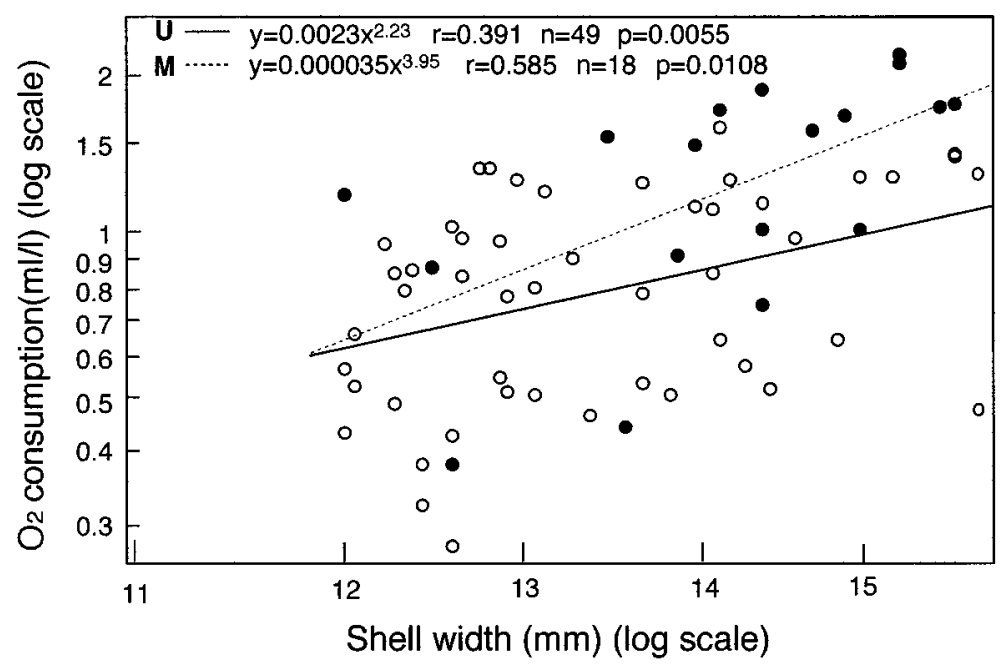

Fig. 1. Comparison of oxygen consumption between $U$-snails and $M$-snails. For $\mathrm{U}$-snails, only data in the ranges of $\mathrm{M}$-snails in shell width were used for analysis and plotting. (O) U-snail; (O) M-snail 
growth rate (gigantism) (for reviews, see Minchella 1985, Hurd 1990). The increased oxygen consumption may be a cause of feeding increase, as it is related to feeding frequency, like other basal metabolic parameters such as the heart rate (Von Brand et al. 1948, Williams \& Gilbertson 1983). In Semisulcospira, the nutrient deprivation by trematodes may not cause a reduction in activity, in contrast to Biomphalaria or Hydrobia (Becker 1980, M ouritsen \& J ensen 1994), but the feeding increase may compensate for nutrient deprivation.

In natural conditions, infected Semisulcospira libertina were found at deeper sites more often than Usnails (Shinagawa et al. 1999a). Snails also showed a habitat shift in the laboratory, but the pattern was not the same for the large size class (Shinagawa et al. 1999b). Metabolic changes in the snails might be related to the habitat shift indirectly, at least in the large size class. However, increased feeding conflicts with the finding of deeper distribution of infected snails in the field since their main diet is algae on the upper surface of stones or sediments (M ori 1946). The total crawling activity and tenacity were initially assumed to be the causes of the water-depth shift, but these parameters did not vary with infection category. $M$ ore information on the metabolism of host snails and environmental factors in the field is needed to explain the distribution pattern of infected Semisulcospira in the field.

Acknowledgements. We are grateful to the members of the Laboratory of A nimal Physiology and Ecology, Nara Women's University, for daily help and support.

\section{LITERATURE CITED}

Becker W (1980) Microcalorimetric studies in Biomphalaria glabrata: the influence of Schistosoma mansoni on the basal metabolism. J Comp Physiol 135:101-105

Curtis LA (1990) Parasitism and the movements of intertidal gastropod individuals. Biol Bull 179:105-112

Curtis LA (1993) Parasite transmission in the intertidal zone: vertical migrations, infective stages, and snail trails. J Exp Mar Biol Ecol 173:197-209

Hurd H (1990) Physiological and behavioural interactions

Editorial responsibility: Albert Sparks,

Seattle, Washington, USA between parasites and invertebrate hosts. Adv Parasitol 29:271-318

Ito J (1964) A monograph of cercariae in J apan and adjacent territories. In: Morishita K, Komiya Y, Matsubayashi $\mathrm{H}$ (eds) Progress of medical parasitology in J apan 1. M eguro Parasitological Museum, Tokyo, p 395-550

Ito J (1988) A subsequent monograph of cercariae in J apan (1962-1988). J pn J Parasitol 37:269-322

Levri EP, Lively CM (1996) The effects of size, reproductive condition, and parasitism on foraging behaviour in a freshwater snail, Potamopyrgus antipodarum. Anim Behav 51: 891-901

Makita Y, Urabe M, Nagoshi M (1996) Infection of larval trematodes in freshwater snails Semisulcospira from Nabari River System in Nara and Mie Prefectures I. Observed cercariae and their host species and prevalence. J pn J Parasitol 45:309-315 (in Japanese with English abstract)

Minchella DJ (1985) Host life-history variation in response to parasitism. Parasitology 90:205-216

M ori S (1946) Daily rhythmic activities of two J apanese freshwater snails. I. Contrib Physiol Ecol Kyoto University 60: 1-18, 4 pls (in J apanese with English abstract)

Mouritsen KN, J ensen KT (1994) The enigma of gigantism: effect of larval trematodes on growth, fecundity, egestion and locomotion in Hydrobia ulvae (Pennant) (Gastropoda: Prosobranchia). J Exp Mar Biol Ecol 181:53-66

Shinagawa K, Urabe M, Nagoshi M (1999a) Coomparison of distribution between cercariae-infected and uninfected individuals of the freshwater snail Semisulcospira libertina. Biol Inland Waters 14:45-48 (in Japanese with English abstract)

Shinagawa K, Urabe M, Nagoshi M (1999b) Effects of trematode infection on the water depth of habitat in a freshwater snail, Semisulcospira libertina. Hydrobiologia 397: 171-178

Swennen C (1969) Crawling-tracks of trematode infected Macoma balthica (L.). Neth J Sea Res 4:376-379

Thompson SN, Lee RWK, Mejia-Scales V, Shams El-Din M (1993) Biochemical and morphological pathology of the foot of the schistosome vector Biomphalaria glabrata infected with Schistosoma mansoni. Parasitology 107:275-285

Urabe M (1998) Diel change of activity and movement on natural river beds in Semisulcospira reiniana. Venus 57: 17-27

Von Brand T, Nolan MO, Mann ER (1948) Observations on the respiration of Australorbis glabratus and some other aquatic snails. Biol Bull 95:199-213

Williams CL, Gilbertson DE (1983) Altered feeding response as a cause for the altered heartbeat rate and locomotor activity of Schistosoma mansoni-infected Biomphalaria glabrata

Submitted: February 14, 2001; Accepted: February 28, 2001 Proofs received from author(s): M ay 22, 2001 